\title{
CD5+ T-Cell/Histiocyte-Rich Large B-Cell Lymphoma
}

Chung-Che Chang, M.D., Ph.D., Ellen Bunyi-Teopengco, M.D., Camellia Eshoa, M.D.,

Christopher R. Chitambar, M.D., Bal Kampalath, M.D.

Departments of Pathology (C-CC, EB-T, CE, BK) and Medicine (CRC), Medical College of Wisconsin, Milwaukee, Wisconsin

CD5 expression in neoplastic large B-cells in T-cell/ histiocyte-rich large B-cell lymphoma has not been reported, to the best of our knowledge. Here we describe the first case of CD5 + T-cell/histiocyte-rich large B-cell lymphoma that is well documented by histomorphology, immunohistochemistry, flow cytometry immunophenotyping and sorting, and immunoglobulin heavy-chain gene rearrangement study by polymerase chain reaction. The expression of CD5 in large neoplastic B-cells was demonstrated by immunohistochemistry and multicolor flow cytometry. The clonal nature of the CD5+ neoplastic B-cells was confirmed by rearranged immunoglobulin heavy (IgH) chain with polymerase chain reaction (PCR) of flow cytometry-sorted CD5+l $\mathrm{CD19}+/ \kappa+$ cells. The CD5+ neoplastic large B-cells expressed bcl-6 and MUM1/IRF4 but not CD138 by immunohistochemistry. This suggests that the neoplastic cells may be of late germinal-center B-cell/ early post-germinal center B-cell origin. The patient responded to chemotherapy, CHOP (Cytoxan, doxorubicin, vincristine, and prednisone), and Rituxan very well and is currently in complete remission clinically. We propose that the current case, CD5+ T-cell/histiocyte-rich large B-cell lymphoma, represents a variant of recently reported de novo CD5+ diffuse large B-cell lymphomas. Our patient has had an excellent response to treatment; however, the clinical and biologic significance of CD5 expression in T-cell/histiocyte-rich large B-cell lymphoma requires further studies. Awareness of the CD5+ T-cell/histiocyte-rich large B-cell lymphoma variant will prompt pathologists to perform CD5 immunohistochemical stain in cases of T-cell/ histiocyte-rich large B-cell lymphoma. This will lead

Copyright () 2002 by The United States and Canadian Academy of Pathology, Inc.

VOL. 15, NO. 10, P. 1051, 2002 Printed in the U.S.A.

Date of acceptance: June 6, 2002.

Address reprint requests to: Chung-Che Chang, M.D., Ph.D., Department of Pathology, Medical College of Wisconsin, 9200 W. Wisconsin Avenue, Milwaukee, WI 53226; e-mail: jeffchang@pol.net; fax: 414-805-8444.

DOI: 10.1097/01.MP.0000027624.08159.19 to identifying more cases to understand the clinical and biologic characteristics of this variant.

KEY WORDS: CD5+, T-cell rich/histiocyte-rich large B-cell lymphoma.

Mod Pathol 2002;15(10):1051-1057

T-cell/histiocyte-rich large B-cell lymphoma is currently categorized as a variant of diffuse large B-cell lymphomas in the World Health Organization and revised European-American classification of lymphoid neoplasms $(1,2)$. Although there is no strict criteria used nor a definite agreement on the diagnosis of $\mathrm{T}$-cell/histiocyte-rich large B-cell lymphoma, the majority of the cases should have the following characteristics: (1) a diffuse growth pattern throughout the entire specimen on hematoxylin and eosin stain (2), scattered large neoplastic B cells that make up $<10 \%$ of the total cell population (3), the presence of other cells that are mostly $\mathrm{T}$ cells and histiocytes, and (4) clonality of the neoplastic B cells demonstrated by immunohistochemical and molecular techniques (3-7). It is usually associated with advanced clinical stage at presentation $(3-5,8)$.

T-cell/histiocyte-rich large B-cell lymphoma appears to be a heterogeneous group of B-cell lymphomas, which may arise de novo but may also be associated with other lymphomas such as follicular lymphoma and lymphocyte-predominant Hodgkin's disease (7, 9-11). Molecular analysis of T-cell/ histiocyte-rich large B-cell lymphoma has shown that the rearranged immunoglobulin (Ig) genes in the majority of cases carry somatic mutation. This finding indicates that these B cells are derived from germinalcenter B cells (12).

Recently, de novo CD5+ diffuse large B-cell lymphomas has been reported by several groups of investigators who proposed that this lymphoma is a distinct subtype of diffuse large B-cell lymphomas (13-21). We describe here, to the best of our knowledge, the first case of CD5+ T-cell/histiocyte-rich large B-cell lymphoma. Expression of CD5 in the neoplastic large B cells is demonstrated by immu- 
nohistochemistry and by flow cytometry. Furthermore, the clonal nature of the CD5 + neoplastic large B-cells is confirmed by $\kappa$ light-chain restriction and rearranged immunoglobulin heavy $(\operatorname{IgH})$ chain using flow cytometry and polymerase chain reaction (PCR), respectively.

\section{CASE REPORT}

A 47-year-old white male presented to our hospital with a 4-month history of intermittent fever $\left(99-103^{\circ} \mathrm{F}\right)$, chills, sweating, weakness, and a $25-\mathrm{lb}$ weight loss. He denied any significant medical history. The patient worked as an assembly worker for a tractor manufacturing plant. He did not smoke and occasionally drank beer. The patient's mother had died of lymphoma; his father was living with prostate cancer.

His physical examination was unremarkable except for an enlarged spleen that was confirmed by abdominal computed tomography (CT) scan, which showed the spleen measuring $17 \mathrm{~cm}$ in craniocaudal dimension. There was a palpable right inguinal lymph node but no other lymphadenopathy verified by chest and pelvic CT scan. His complete blood cell count was significant for normocytic/ normochromic anemia (hemoglobin: $9.8 \mathrm{~g} / \mathrm{dL}$, hematocrit: 30\%, MCV: 81 fL, MCH: 27 pg, MCHC: 33 $\mathrm{g} / \mathrm{dL}$ ) and leukocytosis (white blood cell count: $19,000 / \mathrm{mm}^{3}$ ) with neutrophilia (72\%), monocytosis (18\%), and a few atypical lymphocytes. Elevated serum levels of alkaline phosphatase (385 U/L) and LDH (368 U/L) were also present. Other studies showed negative results for viral, fungal, and bacterial infection. He subsequently underwent a lymph node biopsy, bone marrow biopsy, splenectomy, and liver biopsy. The results of pathologic evaluation revealed the diagnosis of CD5 + T-cell/ histiocyte-rich large B-cell lymphoma involving lymph node, bone marrow, spleen, and liver.

The patient underwent treatment with combination chemotherapy consisting of Cytoxan, doxorubicin, vincristine, and prednisone (CHOP), in conjunction with Rituxan administrated every 3 weeks. Within 2 weeks of the first cycle of treatment, his symptoms of fever, chills, and sweats abated. Reevaluation with CT scan and bone marrow biopsy after six cycles of therapy revealed no evidence of residual disease. At this time, 6 months after completion of therapy, he has regained weight, feels healthy, and remains in complete remission.

\section{MATERIALS AND METHODS}

\section{Histology and Immunohistochemistry}

The tissue specimens including lymph node, spleen, liver, and bone marrow biopsies were fixed in formalin or Bouin's solution and paraffin embedded. Four-micrometer sections were stained with hematoxylin and eosin. Immunohistochemical stains were performed on the lymph node specimen for the following markers (Table 1): CD3, CD10, CD5, CD15, CD20, CD23, CD30, CD68, CD138, cyclin D1, EpsteinBarr virus (EBV)-LMP, MUM1/IRF4 (multiple myeloma-1/interferon regulatory factor-4), and bcl-6. All slides were stained using the DAKO automated immunostainer (Carpinteria, CA). CD3 and CD20 stains were also performed on the other specimens. The slides were incubated in labeled streptavidin-biotin for linking and labeled subsequently with diaminobenzidine chromogen. Appropriate positive and negative controls were used in all cases.

\section{DNA Extraction from Lymph Node of Paraffin- Embedded Tissue}

The DNA of lymph node was extracted from the paraffin-embedded tissue with 5 - $\mu$ m sections using established protocol (22). The extracted DNA was further tested by an established $\beta$-globin PCR assay to ensure that the DNA was able to be amplified by PCR (22).

\section{Flow Cytometry}

The mononuclear cells prepared from bone marrow aspirate were incubated with each antibody coupled with various fluorochromes. The antibodies studied included the following: CD2, CD3, CD5, CD4, CD8, CD10, CD19, CD20, $\kappa$ light chain, and $\lambda$ light chain. Three-color flow cytometry surface marker analysis was performed with FACScan flow cytometer (Becton Dickinson, San Jose, CA). The data analysis was done using CELLQuest software (Becton Dickinson).

TABLE 1. Characteristics of the Antibodies Used

\begin{tabular}{llll}
\hline \multicolumn{1}{c}{ Antibody } & \multicolumn{1}{c}{ Clone } & Manufacturer (location) & Dilution \\
\hline CD3 & NA & DAKO (Carpinteria, CA) & $1: 300$ \\
CD5 & CD5/54/F6 & DAKO & $1: 100$ \\
CD10 & $56 C 6$ & Novocastra (Newcastle, & $1: 50$ \\
& & UK) \\
CD15 & Leu-M1 & Becton Dickinson (San & $1: 50$ \\
& & Jose, CA) & $1: 400$ \\
CD20 & L26 & DAKO & $1: 40$ \\
CD23 & IBI2 & Novocastra & $1: 60$ \\
CD30 & Ber-H2 & DAKO \\
CD68 & PGM-1 & DAKO \\
CD138 & MI-15 & DAKO \\
MUM1/IRF4 & M-17 & Santa Cruz Biotechnology & $1: 200$ \\
& & (Santa Cruz, CA) & $1: 200$ \\
Bcl-6 & NA & Santa Cruz Biotechnology & $1: 300$ \\
Cyclin D1 & DSC-6 & DAKO & $1: 25$ \\
EBV-LMP & CS1-4 & DAKO & $1: 50$ \\
\hline
\end{tabular}

The method for epitope retrieval was a heating water bath at $100{ }^{\circ} \mathrm{C}$ with pH 6.0 citrate buffer for 35 minutes for all antibodies except EBVLMP, whose epitope was retrieved by proteinase $\mathrm{K}$ treatment. NA, not applicable, polyclonal; EBV, Epstein-Barr virus. 
For flow cytometry sorting, the mononuclear cells from marrow aspirate were incubated with three antibodies: CD5, CD19, and $\kappa$ light chain in one tube. The sorting was performed using a FACS Vantage flow cytometer/sorter (Becton Dickinson). $\mathrm{CD} 5+/ \mathrm{CD} 19+/ \kappa+$ cells and CD5-/CD19+/ + cells were collected into two separate tubes containing $100 \mu \mathrm{L}$ of proteinase K digestion buffer (proteinase $\mathrm{K}, 1 \mathrm{mg} / \mathrm{mL}$ ). The tubes were incubated at $37^{\circ} \mathrm{C}$ for 36 hours. Then, the proteinase $\mathrm{K}$ was inactivated at $95^{\circ} \mathrm{C}$ for 5 minutes. The DNA in the tubes was then stored at $4^{\circ} \mathrm{C}$ until used.

\section{IgH Gene Rearrangement and $t(14 ; 18)$ Study by Polymerase Chain Reaction}

Polymerase chain reaction (PCR) was performed in a $20-\mu \mathrm{L}$ reaction with consensus primers (23) for Framework Region 3 (FR3) and JH, 100 ng DNA from flow cytometry-sorted cells $(5+/ 19+/$ kappa + or $5-/ 19+/ \mathrm{kappa}+$ ) or paraffin-embedded lymph node tissue, dNTP, Taq polymerase, and $4.0 \mathrm{~mm}$ $\mathrm{Mg}^{2+}$ using Lightcycler (Roche Diagnostic). The sequences of the primers were as follows: 5'CTGTCGACACGGCCGTGTATT ACTG-3' (FR3) and 5'-AACTGCAG AGGAGACGGTGACC-3' (JH). The 40 cycles of reaction were done with denaturation at $94^{\circ} \mathrm{C}$ for 0 second, annealing at $59^{\circ} \mathrm{C}$ for 5 seconds, and extension at $73^{\circ} \mathrm{C}$ for 8 seconds. The PCR products were then loaded on $8 \%$ polyacrymide gel and stained with ethidium bromide.

The PCR reaction for detecting $t(14 ; 18)$ was performed similarly using the primers (5'-AGATGGCAAATGACCAGCAGA-3' and 5'-ACCTGAGGAGACGG TGACC-3') to detect bcl-2/JH rearrangements that occur at the major breakpoint region. The PCR products were then loaded on $2 \%$ agarose gel and stained with ethidium bromide.

\section{RESULTS}

The hematoxylin and eosin (H\&E)-stained sections of the lymph node showed complete effacement of the lymph node architecture by a diffuse lymphocytic infiltrate composed of predominantly small, mature lymphocytes and histiocytes with scattered large neoplastic lymphocytes (Fig. 1, A-B). The large neoplastic lymphocytes, which consisted of $<10 \%$ of total cells, contained vesicular nuclei, irregular and some polylobated nuclear contours, prominent nucleoli, and moderate amount of cytoplasm. These neoplastic cells expressed CD20 (Fig. 1C), CD5 (Fig. 1D), MUM1/IRF4 (Fig. 1E), Bcl-6 (Fig. $1 \mathrm{~F}$ ), and CD30 (partial) but not CD3, CD10, CD23, CD15, CD138, cyclin D1, or EBV-LMP. The background histiocytes were highlighted by CD68 (PG$\mathrm{M} 1$ ), and the small mature lymphocytes were confirmed to be T cells expressing CD3 but not CD20.
The expression of CD5 in the large neoplastic lymphocytes was further confirmed by flow cytometry study performed in marrow specimen, in which involvement by lymphoma was clearly demonstrated by morphology and clonality studies. The marrow aspirate showed scattered large neoplastic lymphocytes with irregular nuclear contour, prominent nucleoli, and moderate amount of cytoplasm. The bone marrow core biopsy displayed a hypercellular marrow with trilineage hyperplasia. There were interstitial lymphoid infiltrates composed of predominantly small lymphocytes (CD3 $+\mathrm{T}$ cells) with scattered large neoplastic lymphocytes (CD20+).

The flow cytometry analysis of marrow aspirate showed a small but distinct population (3\% of total collected events or $16 \%$ of total lymphocytes) of monoclonal B cells that expressed CD5, CD19, bright CD20, and bright $\kappa$ light chain but not CD23 or CD10. The CD $5+/ \mathrm{CD} 19+/ \kappa+$ cells were larger than the reactive $\mathrm{T}$ lymphocytes (CD5+/CD19-/ $\left.\kappa^{-}\right)$by forward light scatter characteristics (Fig. 2).

The sorted CD $5+/ \mathrm{CD} 19+/ \kappa+$ neoplastic B cells showed a rearranged IgH band with a size of about 98 base pairs by PCR (Fig. 3). The sorted CD5-/ CD19+/kappa + cells showed an oligoclonal/polyclonal pattern. This pattern may represent a restricted B-cell repertoire or a neoplastic clone with some clonal diversity generated through somatic hypermutation. The finding that the CD5-/ CD19+/kappa + cells were small in size by forward light scatter characteristics (data not shown), however, favored the former. Both the sorted CD5+/ $\mathrm{CD} 19+/ \mathrm{kappa}+$ cells and sorted CD5-/CD19+/ kappa + cells showed no evidence of $t(14 ; 18)$ by PCR. The DNA extracted from lymph node of the paraffin-embedded section failed to show any clonal B-cell proliferation by IgH gene rearrangement, most likely because of the low amounts of neoplastic cells in the background of abundant reactive $T$ cells and histiocytes (Fig. 4).

The H\&E-stained sections of the liver biopsy show a preserved hepatic architecture with scattered CD20+ large neoplastic lymphocytes infiltrating the sinusoids. The H\&E-stained sections of the spleen revealed unremarkable white pulp. The large neoplastic lymphocytes were scattered in the red pulp and were highlighted by CD20 stain.

\section{DISCUSSION}

Expression of CD5 in neoplastic large B cells in T-cell/histiocyte-rich large B-cell lymphoma, to the best of our knowledge, has not been reported. Here, we describe the first case of T-cell/histiocyte-rich large B-cell lymphoma with CD5 expression in the large neoplastic B cells. This case meets the mor- 

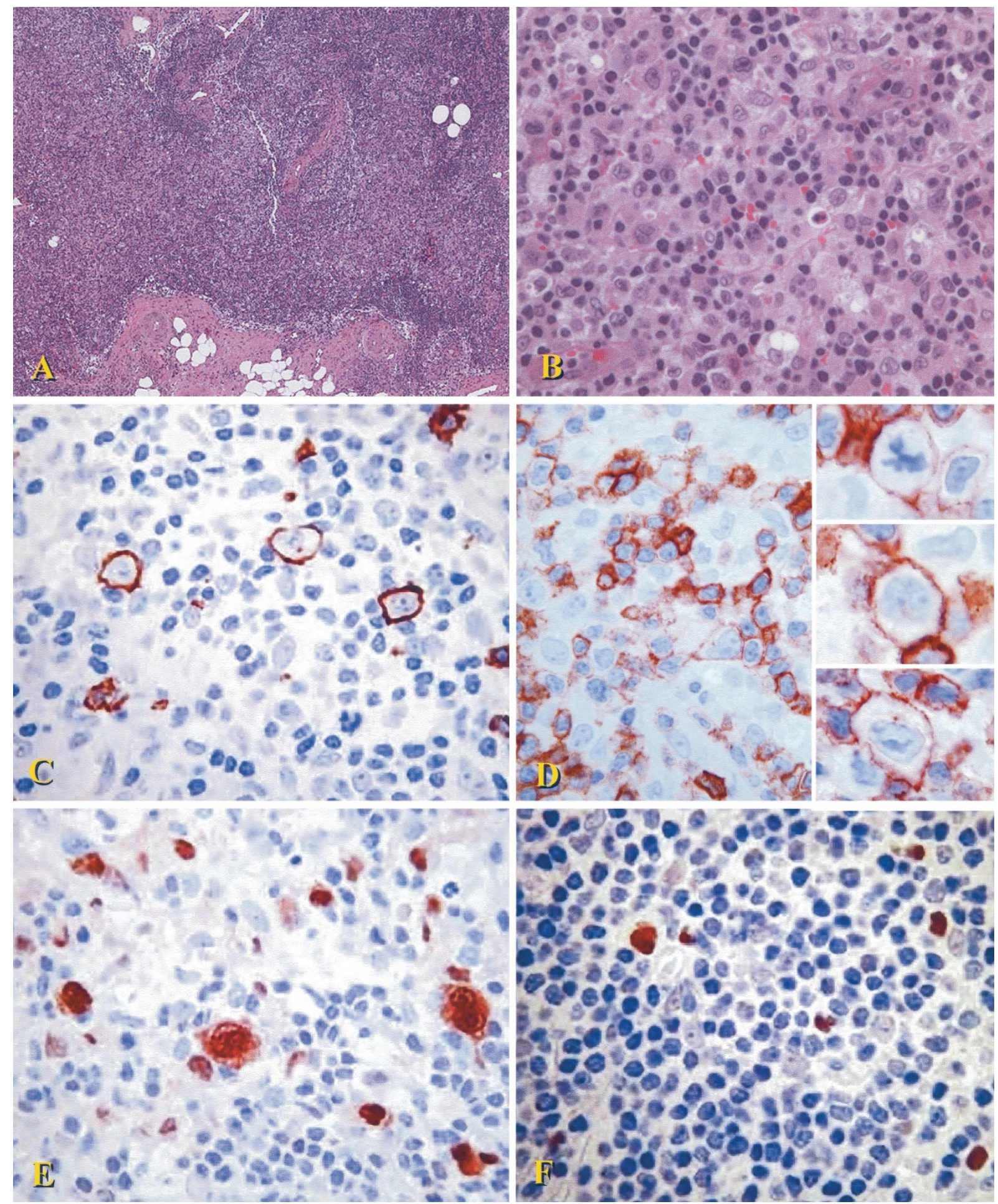

FIGURE 1. The histology and immunohistochemistry of CD5+ T-cell/histiocyte-rich large B-cell lymphoma. A, at low power, normal nodal architecture is replaced by a diffuse lymphocytic infiltrate (hematoxylin and eosin staining [H\&E], 40×). B, at high power, the infiltrate is composed predominantly of small lymphocytes and histiocytes with scattered large neoplastic lymphocytes (H\&E, 400×). C, the large neoplastic lymphocytes express CD20 but not the small reactive lymphocytes (immunostain, 400×). D, the neoplastic cells express CD5 and are surrounded by small reactive T cells, which also express CD5 strongly. The insets highlight the CD5+ neoplastic cells, one cell in mitosis (immunostain, 400×). E, nuclear and cytoplasmic staining of MUM-1/IRF4 is shown in the large neoplastic cells. A few small activated T cells are also positive (immunostain, $400 \times$ ). F, the large neoplastic cells show nuclear expression of bcl-6 (immunostain, 400×).

phologic criteria for a prototype of T-cell/ histiocyte-rich large B-cell lymphoma with the lymph node biopsy showing a diffuse histology with infiltrates of predominantly small reactive $\mathrm{T}$ lym- phocytes and histiocytes with scattered large neoplastic B lymphocytes that make up $<10 \%$ of the entire cellular population. The expression of CD5 was demonstrated by immunohistochemistry in the 

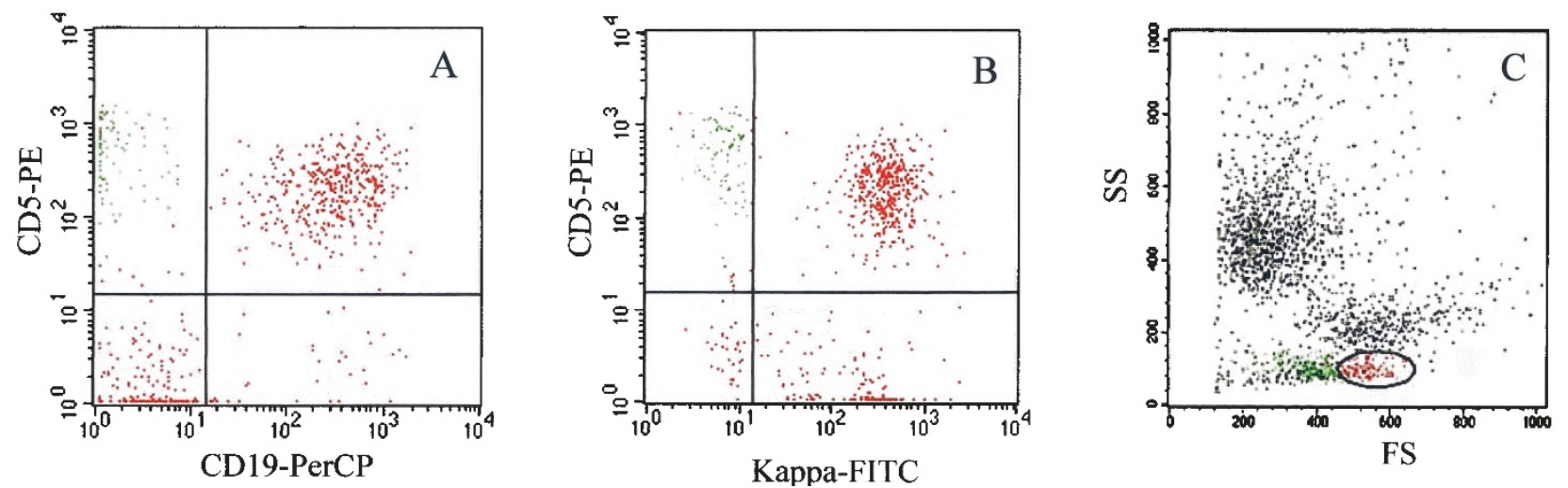

FIGURE 2. The results of flow cytometry study. A and B, the neoplastic lymphocytes (in red) in the marrow aspirate are monotypic, expressing CD5, CD19, and $\kappa$ light chain. C, the neoplastic lymphocytes (in red) are larger than the reactive T lymphocytes (in green, CD5+/CD19-/kappa-) by light scatter characteristics.

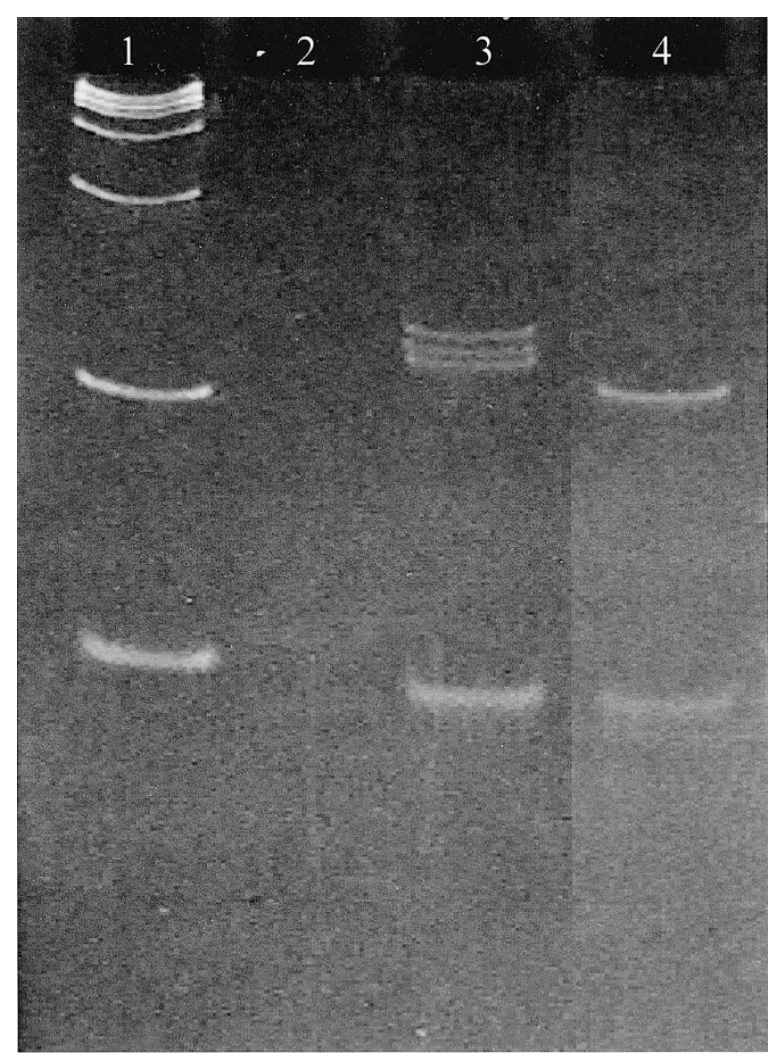

FIGURE 3. The results of immunoglobulin heavy chain rearrangement study on flow cytometry-sorted cells by polymerase chain reaction: the sorted CD5+/CD19+/ $\kappa+$ neoplastic cells from marrow aspirate are monoclonal (Lane 4), with the band at size of 98 base pairs. In contrast, the CD5-/CD19+/ + normal B cells show oligo(poly)clonal pattern (Lane 3). Lane 1 shows molecular weight markers (from bottom to top: 50, 100, 200, 300, 400, 500, and 600 base pairs, respectively), and Lane 2 is the water control. The very distal band (band at size of $<50$ base pairs) in lanes 3 and 4 represents the band from primer-dimer formation.

lymph node specimen and further supported by flow cytometry study in the marrow aspirate. The clonality of neoplastic cells is further established by IgH rearrangement with neoplastic lymphocytes isolated by flow cytometry sorting.

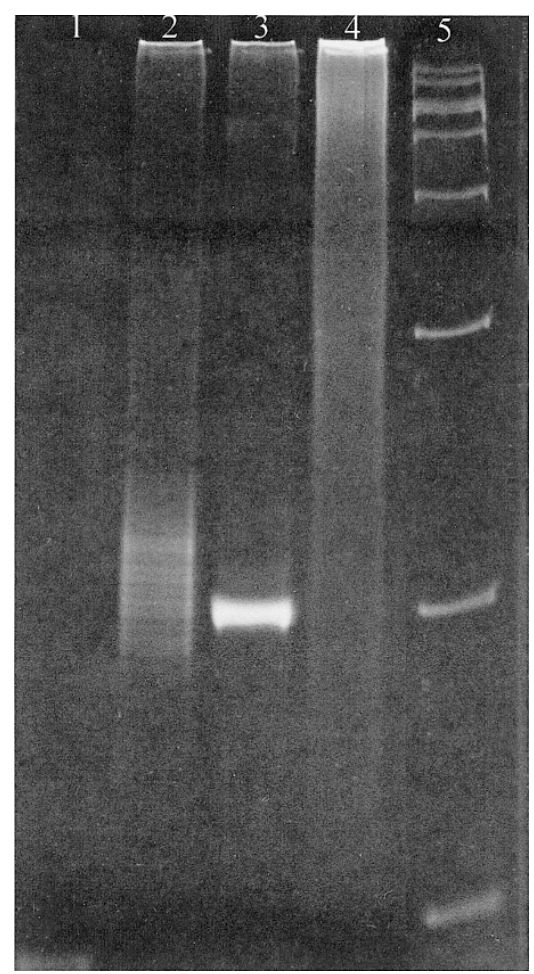

FIGURE 4. The results of immunoglobulin heavy chain rearrangement study on paraffin-embedded lymph node tissue by polymerase chain reaction: there is no clonal band identified in the lymph node, most likely due to the small amount of neoplastic cells in the background of abundant T cells and histiocytes (Lane 4). Lanes 1 to $\mathbf{3}$ represent water control, polyclonal control (tonsil), and positive control (B-cell lymphoma cell line, Namalwa), respectively. Lane 5 is the molecular weight ladder (from bottom to top: 50, 100, 200, 300, 400, 500, and 600 base pairs, respectively). The very faint distal band (band at size of $<50$ base pairs) in Lane 1 represents band from primer-dimer formation.

The most unique presentation of this case is the expression of CD5 in the large neoplastic lymphocytes. Immunohistochemical stains and flow cytometry study confirm this finding. CD5 expression in large B cells is very unusual, although it is common in B-cell chronic lymphocytic leukemia/small lymphocytic lymphoma and mantle cell lymphoma. 
$\mathrm{CD} 5+$ de novo diffuse large $\mathrm{B}$-cell lymphomas is recently identified as a rare variant of diffuse large B-cell lymphomas and was first described by Matolcsy et al. in 1995 (20). They reported nine CD5positive diffuse large B-cell lymphomas that expressed CD19, CD22, CD20, and monotypic immunoglobulin but not CD3, CD10, CD23, or CD30. These cases lacked integration of the Epstein-Barr virus genome and structural alterations of the bcl-1, bcl-2, c-myc, H-ras, K-ras, and $\mathrm{N}$-ras proto-oncogenes and the p53 tumor suppressor gene. However, bcl-6 proto-oncogene rearrangement was found in four cases $(44.4 \%)$. This is comparable with the frequency of bcl- 6 gene rearrangement in CD5-negative diffuse large B-cell lymphomas (20). They suggested that de novo CD5+ diffuse large B-cell lymphomas are genotypically similar to CD5-negative diffuse large B-cell lymphomas (20).

Further studies have suggested that CD5+ diffuse large B-cell lymphomas are heterogeneous; most cases do not seem to be related to chronic lymphocytic leukemia or mantle cell lymphoma $(15,18$, 19). Studies by Taniguchi et al. and Kume et al. (18, 19) have shown somatic hypermutations in the IgH gene of the CD5+ diffuse large B-cell lymphomas. This finding suggests that CD5+ diffuse large B-cell lymphomas were derived from the same maturation stage as were CD5- diffuse large B-cell lymphomas, that is, those from germinal-center B cells or post-germinal center B-cells (18). However, others have suggested that the histogenesis of CD5+ diffuse large B-cell lymphomas may be different from that of CD5- diffuse large B-cell lymphomas because of the differences in the frequencies of somatic mutation and ongoing mutation rates (13).

Clinically, de novo CD5 + diffuse large B-cell lymphomas tend to be elderly onset (median age, 63 years; range, 37-91 years), with female predominance. Most patients had extranodal involvement at presentation. In comparison with the patients with CD5-negative diffuse large B-cell lymphomas, the treatment outcome for the patients with de novo $\mathrm{CD} 5+$ diffuse large B-cell lymphomas was very poor with frequent relapse $(18,16,21)$. The failure-free survival curve was almost identical to that of patients with mantle cell lymphoma. These findings suggest that de novo CD5+ diffuse large B-cell lymphomas form a distinct subgroup of diffuse large B-cell lymphomas $(18,16,21)$.

We propose that the current case, CD5+ T-cell/ histiocyte-rich large B-cell lymphoma, represents a variant of $\mathrm{CD} 5+$ diffuse large B-cell lymphomas in agreement with the current concept of recognizing CD5-negative T-cell/histiocyte-rich large B-cell lymphoma as a variant of CD5-negative diffuse large B-cell lymphomas. We hypothesize that the CD5+ large neoplastic lymphocytes in this case may arise from the same B cells that give rise to the recently identified $\mathrm{CD} 5+$ de novo diffuse large B-cell lymphomas. The expression of bcl- 6 and MUM1/IRF4 but not CD138 by the neoplastic lymphocytes suggests that the histogenesis of these lymphocytes is most likely late-germinal center Bcell/early post-germinal center B-cell origin (24, 25). The lack of expression of cyclin D1 rules out the relationship with large-cell variant of mantle cell lymphoma (26). The absence of preceding lymphocytosis, the bright CD20 as well as bright light-chain expression, and the lack of CD23 expression argue against the case arising from transformation of B-cell chronic lymphocytic leukemia/small lymphocytic lymphoma.

Our patient has had an excellent response to treatment and is currently in complete remission. However, the clinical and biologic significance of CD5 expression in T-cell/histiocyte-rich large B-cell lymphoma requires further studies. Awareness of the CD5 + T-cell/histiocyte-rich large B-cell lymphoma variant will prompt pathologists to perform CD5 immunohistochemical stain in cases of T-cell/ histiocyte-rich large B-cell lymphoma. This will lead to identifying more cases to understand the clinical and biologic characteristics of this variant.

Acknowledgments: The authors appreciate the technical support during this work from Glen A. Dawson, B.S., H.T.\& I.H.C. (A.S.C.P.), Bernard C. Schur, B.S., and Joshua Johnson, B.S.

\section{REFERENCES}

1. Harris NL, Jaffe ES, Diebold J, Flandrin G, Muller-Hermelink HK, Vardiman J, et al. The World Health Organization classification of hematological malignancies report of the Clinical Advisory Committee Meeting, Airlie House, Virginia, November 1997. Mod Pathol 2000;13:193-207.

2. Harris NL, Jaffe ES, Stein H, Banks PM, Chan JK, Cleary ML, et al. A revised European-American classification of lymphoid neoplasms: a proposal from the International Lymphoma Study Group. Blood 1994;84:1361-92.

3. Baddoura FK, Chan WC, Masih AS, Mitchell D, Sun NC, Weisenburger DD. T-cell-rich B-cell lymphoma. A clinicopathologic study of eight cases. Am J Clin Pathol 1995;103: 65-75.

4. Macon WR, Williams ME, Greer JP, Stein RS, Collins RD, Cousar JB. T-cell-rich B-cell lymphomas. A clinicopathologic study of 19 cases. Am J Surg Pathol 1992;16:351-63.

5. Krishnan J, Wallberg K, Frizzera G. T-cell-rich large B-cell lymphoma. A study of 30 cases, supporting its histologic heterogeneity and lack of clinical distinctiveness. Am J Surg Pathol 1994;18:455-65.

6. Ramsay AD, Smith WJ, Isaacson PG. T-cell-rich B-cell lymphoma. Am J Surg Pathol 1988;12:433-43.

7. Delabie J, Vandenberghe E, Kennes C, Verhoef G, Foschini MP, Stul M, et al. Histiocyte-rich B-cell lymphoma. A distinct clinicopathologic entity possibly related to lymphocyte predominant Hodgkin's disease, paragranuloma subtype. Am J Surg Pathol 1992;16:37-48. 
8. Skinnider BF, Connors JM, Gascoyne RD. Bone marrow involvement in T-cell-rich B-cell lymphoma. Am J Clin Pathol 1997;108:570-8.

9. De Jong D, Van Gorp J, Sie-Go D, Van Heerde P. T-cell rich B-cell non-Hodgkin's lymphoma: a progressed form of follicle centre cell lymphoma and lymphocyte predominance Hodgkin's disease. Histopathology 1996;28:15-24.

10. Schmidt U, Metz KA, Leder LD. T-cell-rich B-cell lymphoma and lymphocyte-predominant Hodgkin's disease: two closely related entities? Br J Haematol 1995;90:398-403.

11. Schmidt U, Leder LD. T-cell-rich B-cell lymphoma-a distinct clinicopathologic entity? Leuk Lymphoma 1996;23:17-24.

12. Brauninger A, Kuppers R, Spieker T, Siebert R, Strickler JG, Schlegelberger B, et al. Molecular analysis of single B cells from T-cell-rich B-cell lymphoma shows the derivation of the tumor cells from mutating germinal center B cells and exemplifies means by which immunoglobulin genes are modified in germinal center B cells. Blood 1999;93:2679-87.

13. Nakamura N, Kuze T, Hashimoto Y, Hara Y, Hoshi S, Sasaki $\mathrm{Y}$, et al. Analysis of the immunoglobulin heavy chain gene variable region of CD5-positive and -negative diffuse large B cell lymphoma. Leukemia 2001;15:452-7.

14. Nakamura N, Kuze T, Hashimoto Y, Hoshi S, Tominaga K, Sasaki Y, et al. Analysis of the immunoglobulin heavy chain gene of secondary diffuse large B-cell lymphoma that subsequently developed in four cases with B-cell chronic lymphocytic leukemia or lymphoplasmacytoid lymphoma (Richter syndrome). Pathol Int 2000;50:636-43.

15. Kroft SH, Howard MS, Picker LJ, Ansari MQ, Aquino DB, McKenna RW. De novo CD5+ diffuse large B-cell lymphomas. A heterogeneous group containing an unusual form of splenic lymphoma. Am J Clin Pathol 2000;114:523-33.

16. Yamaguchi M, Ohno T, Oka K, Taniguchi M, Ito M, Kita K, et al. De novo CD5-positive diffuse large B-cell lymphoma: clinical characteristics and therapeutic outcome. $\mathrm{Br} \mathrm{J}$ Haematol 1999;105:1133-9.

17. Nakamura N, Hashimoto Y, Kuze T, Tasaki K, Sasaki Y, Sato $\mathrm{M}$, et al. Analysis of the immunoglobulin heavy chain gene variable region of CD5-positive diffuse large B-cell lymphoma. Lab Invest 1999;79:925-33.
18. Taniguchi M, Oka K, Hiasa A, Yamaguchi M, Ohno T, Kita K, et al. De novo CD5+ diffuse large B-cell lymphomas express VH genes with somatic mutation. Blood 1998;91:1145-51.

19. Kume M, Suzuki R, Yatabe Y, Kagami Y, Miura I, Miura AB, et al. Somatic hypermutations in the $\mathrm{VH}$ segment of immunoglobulin genes of CD5- positive diffuse large B-cell lymphomas. Jpn J Cancer Res 1997;88:1087-93.

20. Matolcsy A, Chadburn A, Knowles DM. De novo CD5positive and Richter's syndrome-associated diffuse large B cell lymphomas are genotypically distinct. Am J Pathol 1995; 147:207-16.

21. Harada S, Suzuki R, Uehira K, Yatabe Y, Kagami Y, Ogura M, et al. Molecular and immunological dissection of diffuse large B cell lymphoma: CD5+, and CD5- with CD10+ groups may constitute clinically relevant subtypes. Leukemia 1999;13:1441-7.

22. Sato Y, Sugie R, Tsuchiya B, Kameya T, Natori M, Mukai K. Comparison of the DNA extraction methods for polymerase chain reaction amplification from formalin-fixed and paraffinembedded tissues. Diagn Mol Pathol 2001;10:265-71.

23. Slack DN, McCarthy KP, Wiedemann LM, Sloane JP. Evaluation of sensitivity, specificity, and reproducibility of an optimized method for detecting clonal rearrangements of immunoglobulin and T-cell receptor genes in formalinfixed, paraffin-embedded sections. Diagn Mol Pathol 1993;2:223-32.

24. Falini B, Fizzotti M, Pucciarini A, Bigerna B, Marafioti T, Gambacorta M, et al. A monoclonal antibody (MUM1p) detects expression of the MUM1/IRF4 protein in a subset of germinal center B cells, plasma cells, and activated T cells. Blood 2000;95:2084-92.

25. Carbone A, Gloghini A, Larocca LM, Capello D, Pierconti F, Canzonieri V, et al. Expression profile of MUM1/IRF4, BCL-6, and CD138/syndecan-1 defines novel histogenetic subsets of human immunodeficiency virus-related lymphomas. Blood 2001;97:744-51.

26. Dunphy CH, Perkins SL. Large cell variants of CD5+, CD23B-cell lymphoma/leukemia. Arch Pathol Lab Med 2001;125: 513-8. 